\title{
Assessment of Nurses Knowledge Regarding Care of Child with Respiratory Distress Syndrome in Ahmed Gasim Pediatric Hospital, Bahri, Sudan 2018
}

\section{Eiman Ahmed Saad*}

Department of Pediatric Nursing, Sudan International University, Sudan

*Corresponding Author: Eiman Ahmed Saad, Department of Pediatric Nursing, Sudan International University, Sudan.

Received: September 26, 2019; Published: October 21, 2019

\begin{abstract}
Background: preterm infants are at risk for respiratory distress syndrome which defined as a breathing disorder resulting from lung immaturity. Respiratory distress syndrome is a life threatening lung disorder that result from undeveloped and small alveoli and insufficient level of pulmonary surfactant.

Objective: The aim of this study was to assess the nurses' knowledge regarding care of child with respiratory distress syndrome in Ahmed Gasim Pediatric Hospital.

Method: It was a descriptive cross sectional hospital base study was carried out in Ahmed Gasim hospital, convenient sample composed of 52 nurses who were working in hospital and providing the care for the child with RDS, whereas. Data were collected through using interview Questionnaire that used to assess the nurses' knowledge regarding care of child with RDS.

Results: The current study revealed that most of nurses had good knowledge regarding the respiratory distress syndrome, and daily care of child.

Conclusion: The most of nurses have poor knowledge regarding how to position the child and where put the child maintain the body temperature.

Recommendation: The study recommended to providing educational program for nurses for improving of nursing care of child with respiratory distress syndrome and Providing updating from respiratory distress syndrome.
\end{abstract}

Keywords: Assessment; Nurses; Knowledge; Care; Child; Respiratory; Distress; Syndrome

\section{Background}

Distress syndrome, also known as Hyaline membrane disease HMD, is a life threatening lung disorder that result from undeveloped and small alveoli and insufficient level of pulmonary surfactant [1]. It has been widely booklets, pamphlets and boosters for nurses to upgrading their knowledge about child suffering.

Respiratory recognized as a major clinical problem worldwide, carrying a high morbidity and mortality burden, settings RDS affects approximately $70 \%$ of infants born at less than 33 weeks gestation. The incidence and severity of RDS increases with decreasing gestational age and birth weight, affecting approximately $80 \%$ of preterm infants born between 26-286 weeks and $45 \%$ of infants born between 29-326 weeks gestation [2].

Respiratory distress is one of the most common reasons an infant is admitted to the neonatal intensive care unit. Fifteen percent of term infants and $29 \%$ of late preterm infants admitted to the neonatal intensive care unit develop significant respiratory morbidity; this is even higher for infants born before 34 weeks' gestation [3].

The significant cause of RDS is deficiency of alveolar surfactants due to immaturity of Type II pneumocyte, resulting low compliance of lungs, alveolar surface tension, decreased gas exchange and a de- 
mand for high ventilatory pressures The clinical manifestation of RDS includes apnea, cyanosis, grunting, inspiratory stridor, nasal flaring, poor feeding, tachypnea, retractions in the intercostal, subcostal, or suprasternal spaces. These signs and symptoms are present at birth or shortly afterwards with getting worse over the first 48 - 72 hours of infant's life [4].

Infant with RDS have poor lung compliance, they generally require Mechanical ventilation and supplemental oxygen, leading to interstitial edema and epithelial destruction [2].

Medical management of newborn with RDS is focused on continuous pulse oximetry, Arterial Blood Gases(ABG), The Partial Pressure of Oxygen in Arterial Blood (PaO2) should be maintained in the normal range of 50 to $70 \mathrm{mmHg}$ and a pulse oximetry reading of 90\%. Endo Tracheal Tube (ETT) and exogenous surfactant as indicated for neonates at risk for RDS [1].

RDS is currently managed with one or a combination of the following therapies: mechanical ventilation, oxygen therapy, exogenous surfactant therapy and non-invasive respiratory support which includes nasal continuous positive airway pressure (CPAP) or noninvasive intermittent positive airway pressure (NIPPV). RDS in preterm infants can cause lung injury which puts them at a greater risk of developing bronchopulmonary dysplasia (BPD) [2]. If untreated, RDS will worsen. It appears to be a self-limiting disease, with respiratory symptoms declining after 72 hours. This decline parallels the production of surfactant in the alveoli. Nursing care for infant with RDS is demanding crucial part requiring alert, skillful, and sensitive nurse. The care involve review the history for risk factors associated with RDS. The neonatal mortality rate reflects not only the quality of women care during pregnancy but also the quality of infants care during the first month of life [5-23].

\section{Objective}

\section{General objectives}

To assessment of nurse's knowledge regarding care of child with respiratory distress syndrome in Ahmed Gasim pediatric hospital, Khartoum, Sudan 2018.

Specific objectives

- To assess the knowledge among nurse's about identification the disease, causes, signs and symptoms, diagnosis, treatment and complication.
- $\quad$ To assess the nursing knowledge about care that provided to the child suffering from respiratory distress syndrome.

- To determine whether or not nurse's have adequate knowledge about care of child.

\section{Discussion}

Respiratory Distress Syndrome (RDS) or Hyaline Membrane Disease (HMD) is one of the most common problems of Premature babies. It can cause babies to need extra oxygen and Help breathing. The course of illness with RDS depends on the Size and gestational age of the baby, the severity of the disease, the presence of infection; hether or not the baby needs. Mechanical help to breathe. RDS typically worsens over the first 48 to 72 hours. RDS has been widely recognized as a major. Clinical problem worldwide, carrying a high morbidity and Mortality. So that, This study aimed to assess nurses knowledge. Regarding nursing care of child with RDS and prevent future Complication. The results of this study shown in figure (1) the majority of study sample age (30-40)years, and they are accounted for (20) nurses With present (38.5\%).this result is disagrees with study done byziz A, Mansi Q 2017 who was study( assessment quality of Nursing care provided to neonates with respiratory distress. Syndrome at intensive care unit in al-nasiriyah city hospital)Witch find that the majority of study sample with age (20-30). According to the subject's gender the majority of the sample are Female for $(94.2 \%)$ of the total sample. Concerning to the educational levels, the greater number had Diploma degree. The majority of the sample (27) nurses and they accounted for (51.9\%) of the total sample. This result agree with study done by [Ahmed L, Said N, Mohamed S 2013] who study nursing care provide for neonates with respiratory distress syndrome in the neonatal intensive care unite) it was found that more than half of nurses had diploma and nearly one third of them had bachelor degree, and disagrees with study done by [Loutfy, A, Mohamed, A (2014)], who study (quality of nursing care provided for preterm infants suffering from respiratory distress syndrome) that reveals the majority of study sample with bachelor's degree in nursing. Regarding to years of experience, the results indicated that a highest percentage of the study sample are 10-15 years and they are (36.5\%) nurses. This result disagrees with study done by Ahmed, G and Abosamra, (2015). This study shows the majority of study sample (68\%) have less five years of experience. Concerning to the nurses participation in caring of child with RDS, around (98\%) of the sample have been participated in these. This result was agrees with Aziz A, Mansi Q 
(2013), that show participate in the training program with sample group (yes) and they are (41\%) nurses(8).Assess the studies nurses knowledge about care of child with RDS to proses stander measure. regarding to the studies nursing knowledge about definition, and cases of RDS, the present study showed that a majority of nurses more than three quarters of studies nurses had complete answers, this is disagree with study done by [Ahmed L, Said N, Mohamed S, 2013] who found that approximately two thirds of studied nurses had unsatisfactory knowledge regarding RDS. While regard symptom, diagnoses and treatment the present study showed that a majority of nurses (96\%) are had a right answers. This may be due to increase the level of education and more experience years. The present study showed that no one of study nurses had poor level of knowledge about daily care and role toward administrated oxygen. the nurses knowledge more developed in this. Due to more practice, increase the years of experience of nurses, this finding were convergent with Loutfy A, Mohamed, A. (2014) who studies the quality of nursing provided for preterm infants suffering from RDS. Also this study shows that all nurses are complete knowledgeable regard determine the oxygen ratio and, intervention when baby difficult to breath, due to increase the rate of using oxygen therapy and pulse ox meter for child with RDS.

Regard accumulation of secretions and how to prevent child from alter body nutrition all of nurses had completely answers right, due to daily care and implementation that provided to the child. also this study showed more than half of nurses had complete answer about assessing the respiratory states and sequences of vital signs, due to increase immediate intervention and for child with RDS. But unfortunately, the current study illustrate that most of nurses had poor knowledge about where child must be placed to maintain there body temperature.

\section{Conclusion}

The purpose of the current study was to determine nursing knowledge regarding care of child with respiratory distress syndrome. The most obvious finding to emerge from this study are there is a good knowledge regarding nursing care of child with respiratory distress syndrome. But there are poor knowledge about where child must be placed to maintain there body temperature.

\section{Recommendation}

Based on the study findings and conclusion the following; Recommendation are badly required to be implemented
1. Is important to provide educational program for nurses to Increase knowledge about care of child who suffering from Respiratory distress syndrome and the nursing role to ward this child.

2. There should be provide poster sheet putting in the pediatric Emergency and words concerning daily nursing care and practice for the nurse.

3. Providing updating booklets, pamphlets and boosters for Nurses to upgrading their knowledge about neonatal Respiratory distress syndrome.

4. The facilities which need for complete nursing care to this Child should be available to assist the nurses to give proper care.

5. Encourage the nurses to do well by motivation and increase the salary

6. Comprehensive simple intervention plans needed when caring of the child and maximizing the skills.

7. Continuing education for nurses, integrating of services and Monitoring and evaluation of progresses.

\section{Bibliography}

1. Loutfy, A., et al. "Quality of nursing care provided for preterm infants". Portsaid Scientific Journal of Nursing (2014).

2. Read B. "Evaluation of practice guideline for the management of respiratory distress syndrome in preterm infants". Journal of Public Health Nursing and Medical (2014).

3. Aziz A and Mansi Q. "Assessment Quality of Nursing Care Provided to Neonates with Respiratory Distress Syndrome at Intensive Care Unit in AL- Nasiriyah City Hospitals KUFA". Journal for Nursing Sciences (2017).

4. "Respiratory distress syndrome of the newborn fact sheet". American Lung Association (2007).

5. Christian L and Hermansen J. "Respiratory distress in newborn”. American Family Physician (2007).

6. Gupta S. "The short textbook of paediatrics". 12th edition. New Delhi. Publishers (p) Ltd. (2016).

7. Robert M., et al. "Nelson textbook of pediatric". 20 ${ }^{\text {th }}$ Edition. Canada. Elsevier saunders (2011).

8. Pillitteri A. Maternal and child health nursing. 6th edition. China. williams and wilkins (2010). 
9. Sicker N and Kotecha S. "Pathophysiology of respiratory distress syndrome". American Journal of Pediatric 147 (2005): 446-450.

10. "Neonatal respiratory distress syndrome". In: Medline Plus Medical Encyclopedia (2008).

11. William W., et al. "Current diagnosis and treatment pediatrics. 20th edition. McGraw-Hill companies

12. https://www.britannica.com/science/respiratory-distresssyndromeof-newborns

13. Khalessi N., et al. "The Incidence of Respiratory Distress Syndrome among Preterm Infants Admitted to Neonatal Intensive Care Unit". Open Journal of Pediatrics (2015).

14. Lewicka M., et al. "Non-invasive respiratory supportin newborn - nursing care. Journal of public health, nursing and medicalrece. 2.2013.

15. Shakur S. Illustrated text book of pediatrics. 2nd edition. New Delhi. Jaypee brothers medical publishers (p) Ltd. (2015).

16. https://en.wikipedia.org/wiki/Infant_respiratory_distress_ syndrome

17. Gupta P. Text book of pediatrics. first edition. India. Satish $\mathrm{Ku}-$ mar Jan CBS (2013).

18. https://www.apollohospitals.com/patient-care/health-andlifestyle/diseases-and-conditions/hyaline-membrane-disease

19. St. Louis Children's Hospital One Children's ace.

20. https://www.nhlbi.nih.gov/health-topics/respiratory-distresssyndrome

21. https://www.merriamwebster.com/dictionary/respiratory\%20distress\%20syndrome
22. Singh M. Care of the newborn. 8th edition. India. Satish Kumar Jain CBS. (2015).

23. Ahmed L., et al. "Nursing care provided for neonates with respiratory distress syndrome in the neonatal intensive care units at Makkah Al-Mukarramah in Saudi Arabia". Life Science Journal (2013).

Volume 2 Issue 11 November 2019

(C) All rights are reserved by Eiman Ahmed Saad. 